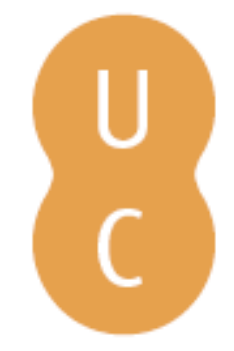

\title{
pommalina
}

\section{Geotecnologia e história ambiental: o uso de detecção de mudança temporal na produção sucroalcooleira em Goiás, Brasil}

\author{
Autor(es): $\quad$ Silva, S. D. e; Silva, N. C. da; Campos, E. S.; Carvalho Junior, O. A. de \\ Publicado por: 2012 \\ URL \\ persistente: URI:http://hdl.handle.net/10316.2/31450 \\ DOI: $\quad$ DOI:http://dx.doi.org/10.14195/978-989-26-0531-9_22 \\ Accessed : $\quad$ 26-Apr-2023 10:27:58
}

A navegação consulta e descarregamento dos títulos inseridos nas Bibliotecas Digitais UC Digitalis, UC Pombalina e UC Impactum, pressupõem a aceitação plena e sem reservas dos Termos e Condições de Uso destas Bibliotecas Digitais, disponíveis em https://digitalis.uc.pt/pt-pt/termos.

Conforme exposto nos referidos Termos e Condições de Uso, o descarregamento de títulos de acesso restrito requer uma licença válida de autorização devendo o utilizador aceder ao(s) documento(s) a partir de um endereço de IP da instituição detentora da supramencionada licença.

Ao utilizador é apenas permitido o descarregamento para uso pessoal, pelo que o emprego do(s) título(s) descarregado(s) para outro fim, designadamente comercial, carece de autorização do respetivo autor ou editor da obra.

Na medida em que todas as obras da UC Digitalis se encontram protegidas pelo Código do Direito de Autor e Direitos Conexos e demais legislação aplicável, toda a cópia, parcial ou total, deste documento, nos casos em que é legalmente admitida, deverá conter ou fazer-se acompanhar por este aviso.

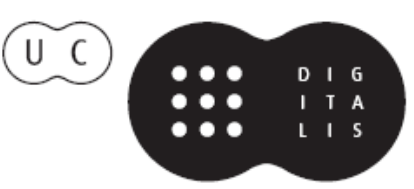





\title{
GEOTECNOLOGIA E HISTÓRIA AMBIENTAL: O USO DE DETECÇÃO DE MUDANÇA TEMPORAL NA PRODUÇÃO SUCROALCOOLEIRA EM GOIÁS, BRASIL
}

\author{
GEOTECHNOLOGY AND ENVIRONMENTAL HISTORY: \\ THE USE OF TIME CHANGE DETECTION IN PRODUCTION \\ OF SUGARCANE IN GOIÁS, BRAZIL
}

S. D. e Silva ${ }^{1}$, N. C. da Silva ${ }^{2}$ E. S. Campos ${ }^{2} \&$ O. A. de Carvalho Junior ${ }^{3}$.

Resumo: Esse trabalho apresenta uma metodologia para analisar a expansão agrícola da cana-de-açúcar para produção sucroalcooleira na microrregiáo de Ceres, Estado de Goiás, região Centro-Oeste brasileira. Essa região, originariamente de vegetação de Cerrado florestal era conhecida, até a primeira metade do século XX como Mato Grosso de Goiás, em função da extensa área de floresta que foi devastada para produção agrícola. O estudo objetiva examinar a mudança temporal do uso da terra a partir de imagens de sensores remoto e construção de mapeamento temático de uso da terra e cobertura vegetal com imagens do satélite Landsat 5, coletados no período de 2005 a 2011 no município de Itapuranga, Estado de Goiás. Consideramos relevante ferramenta para estudos relacionados a História Ambiental na medida em que permite a detecçáo de mudança em diferentes tempos.

Palavras-chave: Expansão sucroalcooleira, História Ambiental do Cerrado, Geotecnologia, Série Temporal.

Abstract: This paper presents a methodology to analyze the agricultural expansion of sugar cane to the production of sugar and ethanol in the microregion of Ceres, State of Goias, Midwest of Brazil. This region, originally of Cerrado vegetation forest was known until the first half of the twentieth century as Mato Grosso of Goiás, because of the extensive forest area which was devastated by the agricultural production. The study aims to examine the land use

\footnotetext{
${ }^{1}$ Universidade Paulista. Email: sandrodutr@hotmail.com.

${ }^{2}$ UniEVANGELICA.

${ }^{3}$ Departamento de Geografia da UnB.
} 
time changes from remote sensor data and the construction of thematic mapping of land use and land cover with Landsat 5 satellite imagery, collected from 2005 and 2011 in the municipality of Itapuranga, State of Goiás. We consider the remote detection a relevant tool for studies related to Environmental History as it allows the recognition of change in different times.

Keywords: Expansion of sugarcane, Change Detection, Environmental History of the Cerrado, Geotechnology.

\section{1 - Introduçáo}

Na busca por fontes renováveis de energia, tem-se estimulado cada vez mais a produção de bioenergias, capazes de atender não somente a crescente demanda energética mundial como também a necessidade urgente na redução dos danos ambientais resultantes da poluição causada pela queima de combustíveis derivados do petróleo. O mapeamento do uso da terra e da paisagem vegetal pode ser feito a partir de sensores colocados em satélites por meio da geração de imagens o que permite conhecer a fisionomia da terra, mensurar o tamanho de áreas degradadas, quantificar a área ocupada por safra agrícola ou alagada em função do represamento de algum curso de água, dentre outros. Logo, as técnicas de Sensoriamento Remoto tornam-se cada vez mais eficazes a proteção ambiental do planeta e ao desenvolvimento do homem em diferentes espaços (JENSEN, 2009).

O presente trabalho procura apresentar os efeitos da devastação do Cerrado decorrente da expansão da produção sucroalcooleira a partir do geoprocessamento de imagens (dados) coletadas de satélites do Instituto Nacional de Pesquisas Espaciais (INPE) tendo como recorte espacial a microrregião de Ceres em Goiás (localizada na mesorregião do Centro Goiano), e mais particularmente o município de Itapuranga, no período entre 2005 a 2011, período em que verificou-se uma grande expansão agrícola para fins sucroalcooleiros.

\section{2 - O conceito de devastação e o seu uso nos estudos do cerrado}

O cerrado destaca-se como um dos principais domínios macro paisagísticos do Brasil e estende-se por diferentes regiōes do território brasileiro, realizando contatos e transiçôes com outros biomas (Fig.1). Mas essa vegetação caracteriza-se pela diversidade fisionômicas que vai desde áreas de campo limpo (herbáceo/subarbustivo) ao cerradão (floresta). Segundo Coutinho (1990) a diversidade na paisagem do Cerrado deve-se, em grande parte, ao reflexo dos diferentes tipos de solo, bem como da incidência de açóes antrópicas no cenário natural. As características ecológicas e geográficas apresentadas remetem a expressiva dimensão territorial e riqueza do bioma cerrado, mas também há de se considerar o intenso processo de devastação ambiental que se iniciou ainda nas primeiras décadas do século XX e que vem alterando de forma avassaladora o cerrado.

O uso do termo devastação é apresentado por Martinez (2006) como um termo recorrente na literatura e bibliografia pertinente, e que esteve presente na historiografia brasileira a partir da primeira metade do século XX. A utilizaçáo desse conceito em nosso texto justifica-se na vinculação deste com modelos agronômicos e historiográficos que nos permite identificar a expansão agrícola no Cerrado. 


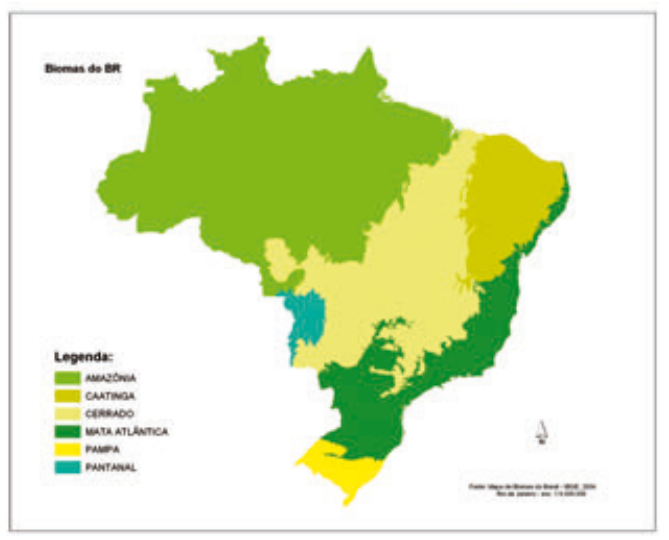

229

Figura 1 - Mapa 1: Biomas Brasileiros. Fonte: IBGE.

No Brasil a "[...] agricultura de tipo monocultor, como a cana-de-açúcar, é apontada como o principal vetor da ocupação territorial e da suspensão da cobertura vegetal do país" (MARTINEZ, 2006, p. 56) indicando o uso do termo "devastação". O autor ainda considera a relevância dessa temática na História Ambiental, na medida em que essa abordagem possibilita retomar um conjunto de problemas intrínsecos à formação da sociedade brasileira, como o uso e a ocupação do solo, as práticas agrícolas e a intensidade da apropriação da terra e dos recursos naturais, bem como a degradação ambiental que lhe seguiu, dentre outros. A conceituação que mais aproxima o termo dos estudos historiográficos é apresentada por Martinez (2006) como uma forma de exploração da natureza que é marcada por um conjunto de características, como, por exemplo, o utilitarismo exacerbado e predatório do solo, marcado por drásticas intervençóes no ecossistema, de finalidade mercantil e caracterizado pela ausência de racionalidade no manejo dos recursos explorados.

\section{3 - A expansão sucroalcooleira em Goiás}

A expansão das plantaçôes canavieiras na microrregião de Ceres em Goiás é um fato construído historicamente, que carrega em si todo um contexto jurídico, sociológico e científico. Esta regiáo experimentou um aumento demográfico significativo a partir das décadas de 1940, quando políticas governamentais foram implantadas para garantir a imigraçáo e povoamento dessa nova área agrícola, que forneceria matérias primas e alimento para abastecer os grandes centros urbanos em expansão no país. Porém, a partir da década de 1980, foi verificado o deslocamento da produçáo de alimentos para a produção dos biocombustíveis. O setor sucroalcooleiro em Goiás, iniciado na década de 1970, quando foram instaladas unidades produtoras nas regióes Centro-Norte e Sudoeste. A expansão do sistema de produção de energia alternativa foi se implantando no restante do estado de Goiás de forma mais lenta, sendo que no final da década de 1990 não havia mais que 15 indústrias instaladas no Estado. A partir dos anos 2000 ocorreu um novo fluxo migratório de empresas e de trabalhadores para Goiás, sendo que a partir 
de 2006 o Estado passou a fazer parte do Plano Nacional de Agroenergia, contando em 2009 com 30 unidades industriais de produção de açúcar e álcool (SILVA et al., 2011).

Os estudos de geoprocessamento da Canasat (2010) apontam para uma expansão significativa de áreas cultivadas, verificando um incremento de $184 \%$ em áreas cultivadas entre as safras agrícolas 2005/2006 para 2010/2011, na microrregião de Ceres, onde localiza-se Itapuranga. Os dados da Canasat (2010) apontam que o município de Itapuranga apresentava em 2005/06 uma área plantada de 406 hectares, saltando para 6.450 hectares para o período de 2010/11, uma expansão agrícola de $1.588 \%$. Isso se deve ao fato de que a usina localizada no município havia sido fechada em função da crise do Proálcool e reabriu recentemente com a retomada dos investimentos em etanol, sob o controle de outra empresa, a Vale Verde Empreendimentos Agrícolas Ltda (MAPA, 2010).

\section{4 - Metodologia para detecção de mudança de uso de solo}

O grupo de pesquisa em análise temporal do Programa de Mestrado em Sociedade, Tecnologia e Meio Ambiente da UniEVANGÉLICA está desenvolvendo um sistema (Software) para análise de mudanças em imagens de séries temporais que permite a quantificação das transformaçóes espaciais registradas por imagens de sensores remotos em diferentes tempos. O sistema está em operação para dados bitemporais utilizando uma abordagem de classificação não-supervisionada denominado Mapas de Características Auto-Organizáveis (KOHONEN, MÄKISARA, 1989) e está se ampliando o método para séries multitemporais e para utilização de algoritmos supervisionados (CARVALHO et al., 2011). A metodologia para o desenvolvimento deste tipo de análise passa pelas seguintes fases: 1. Levantamento de imagens multitemporais de uma mesma região de interesse; 2. Caracterização e seleção de amostras de alvos a serem analisados; e 3. Utilização do software para aplicação de algoritmos de detecção de mudanças nas imagens.

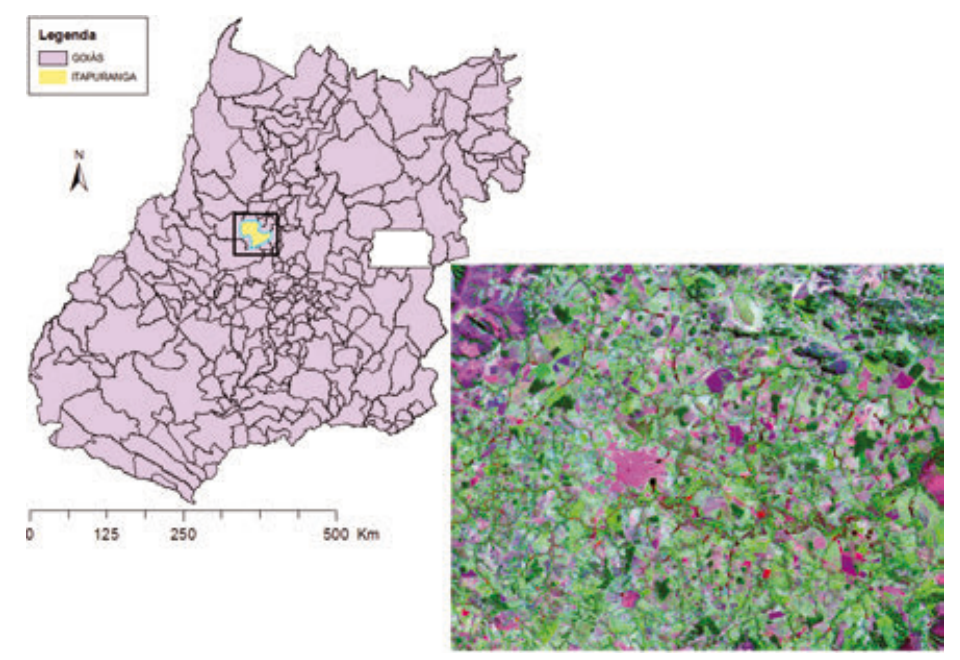

Figura 2. Localização do município de Itapuranga no estado de Goiás, Brasil e imagem de satélite de $09 / 04 / 2005$. 
As figuras 2 e 3 mostram composiçôes RGB com as bandas 3, 4 e 5 do sensor Tematic Mapper (TM) do satélite Landsat 5, respectivamente dos anos de 2005 e 2011 da região do município de Itapuranga localizado no estado de Goiás, Brasil.

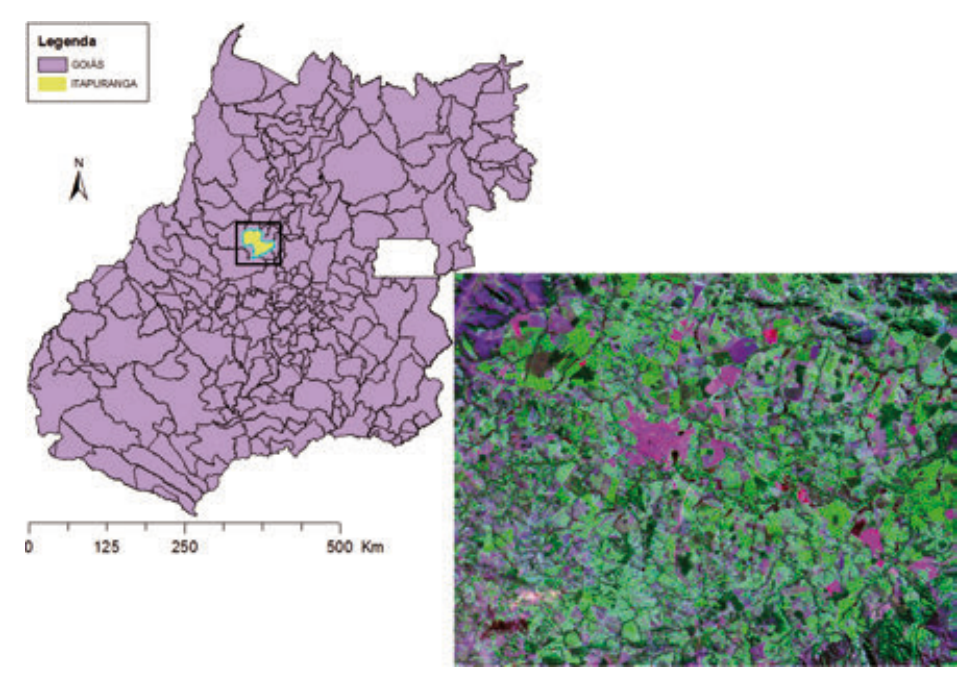

Figura 3. Localização do município de Itapuranga no estado de Goiás, Brasil e imagem de satélite de 26/04/2011.

Com a instrumentação do software de análise de mudanças, as diferenças de distribuiçôes de alvos de interesse entre as imagens de satélites das figuras 1 e 2, podem ser quantificadas. Assim, as evoluçóes e regressóes de monoculturas, tais como cana de açúcar, soja e outras de interesses sociais e econômicos podem ser mapeadas e analisadas do ponto de vista quantitativo e qualitativo.

\section{5 - Conclusões}

Esse estudo é parte de um projeto de pesquisa aprovado pelo Programa Nacional de Cooperação Acadêmica - Novas Fronteiras (CAPES/PROCAD-NF no 21/2009) cujo objetivo geral é analisar a evoluçáo dos processos de mudanças na cobertura do solo em áreas de Cerrado no Estado de Goiás e seus impactos socioambientais, tendo como recorte temporal a década de 1970, marco da expansão das fronteiras agrícolas na região Centro-Oeste do Brasil. Nossa intenção, no pouco espaço que o texto permite, é apresentar parte dessa discussáo, envolvendo as ferramentas de geotecnologias como apoio na discussão das mudanças temporais, sob a orientação dos pressupostos da História Ambiental. Assim, o exercício da multidisciplinaridade nos estudos ambientais ampliam os olhares e as abordagens dos diferentes objetos que as diferentes disciplinas procuram investigar. Portanto, consideramos relevante socializar experiências, mesmo que pesquisas situem em estagio prévio de observação e uso de diferentes procedimentos e ferramentas científicas. 
Desse forma, consideramos que, a partir da expansão desordenada da cultura de cana-de-açúcar, principalmente, na última década, aconteceu e vem acontecendo progressivamente, a degradação do cerrado pelo processo de ocupação humana aliado a falta de políticas públicas de meio ambiente. Diante desse cenário, as áreas nativas vêm diminuindo e várias espécies de fauna e flora são extintas a cada dia.

As imagens de satélite são consideradas fontes seguras por apresentarem informações úteis, que permitem uma visão espacial, espectral e temporal da superfície terrestre. A resolução espacial indica o tamanho do menor objeto que é possível representar em uma imagem; a resolução espectral indica a quantidade de regiốes do espectro eletromagnético nas quais o sensor é capaz de gerar uma imagem em níveis de cinza; a resolução temporal refere-se ao intervalo de tempo em dias ou horas, no qual o sistema demora para obter duas imagens consecutivas da mesma região sobre a terra.

A partir daí, é possível coletar dados de grandes áreas, minimizar os custos e obter resultados estatísticos que sirvam de referencial para a tomada de decisóes e políticas de meio ambiente que possam garantir o desenvolvimento e a preservaçáo ambiental de uma determinada região (FLORENZANO, 2007).

O conhecimento amplo de uma determinada paisagem é de vital importância para adequar ou propor políticas ambientais de preservação e desenvolvimento sustentável a partir das transformaçóes impostas pelo homem. Nesse sentido, as últimas décadas tem evidenciado grande desenvolvimento econômico e degradação ambiental provocadas por destruição de grandes áreas vegetais rurais justificadas pelo intenso processo de urbanização dos munícipios brasileiros.

Em Goiás, esse processo não foi diferente. Nesse viés, a microrregião do Município de Ceres - Goiás ocupa uma área de aproximadamente, 13.163,014 Km² e abrange vinte e dois municípios: Barro Alto, Carmo do Rio Verde, Ceres, Goianésia, Guaraíta, Guarinos, Hidrolina, Ipiranga de Goiás, Itapaci, Itapuranga, Morro Agudo de Goiás, Nova América, Nova Glória, Pilar de Goiás, Rialma, Rianápolis, Rubiataba, Santa Isabel, Santa Rita do Novo Destino, São Luís do Norte, São Patrício e Uruana.

A região possui intensa ação antrópica e são preocupantes os problemas já enfrentados pelas comunidades locais tais como: processos erosivos, contaminaçáo dos mananciais hídricos por agrotóxicos, pecuária extensiva desordenada, despejo de esgoto nos mananciais hídricos, remoção de areia e argila para a construçáo civil, dentre outros.

Nesse sentido, o estudo da paisagem vegetal por técnicas de sensoriamento remoto torna-se eficaz, tanto para permitir um monitoramento que detecte os problemas de devastação e desmatamento de modo a facilitar a obtenção de informaçóes eficazes tanto para a fiscalização ambiental, quanto para a implementação de programas de recuperação do ambiente degradado garantindo um melhor desenvolvimento para as populaçóes envolvidas.

\section{Referencias Bibliográficas}

CANASAT (2010) - Mapeamento de cana via imagens de satélite de observação da terra. Relatório de área de cana, safra e reforma na região Centro-Sul. http://www.dsr.inpe.br/mapdsr/index.jsp. (consultado em 25.07.2010)

CARVALHO Júnior O.A., GUIMARÃES R.F., GILLESPIEA.R., SILVA N.C., GOMES R.A.T (2011). A New Approach to Change Vector Analysis Using Distance and Similarity Measures. Remote Sensing. 
CASTILHO, Denis (2009). A dinâmica socioespacial de Ceres/Rialma no âmbito da modernização em Goiás: território em movimento, paisagens em transição. Dissertação de Mestrado em Geografia. Universidade Federal de Goiás. Goiânia, UFG.

FLORENZANO, Teresa Galloti (2007). Iniciação em Sensoriamento Remoto: Imagens de Satélite para Estudos Ambientais. 2. ed. São Paulo, editora: Oficina de Textos.

IBGE (2011) - Instituto Brasileiro de Geografia e Estatística. IBGE lança o Mapa de Biomas do Brasil e o Mapa de Vegetação do Brasil, em comemoração ao Dia Mundial da Biodiversidade. http://www.ibge.gov. br/home/presidencia/noticias/noticia. (consultado em 02.01.2011)

INSTITUTO NACIONAL DE PESQUISAS ESPACIAIS - INPE. (2012). Divisão de Geração de imagens. Disponível em http://www.dgi.inpe.br/CDSR/. Acesso em: fevereiro de 2012.

JENSEN, John R (2009). Sensoriamento Remoto do Ambiente. 1. ed. São Paulo: Editora Parêntese, 2009. 672 p.

KOHONEN T. e; MÄKISARA K. 1989. The self-organizing feature maps. Physica Scripta, 39: 168.

MAPA - MINISTÉRIO DA AGRICULTURA, PECUÁRIA E ABASTECIMENTO (2010). Relação das Unidades produtoras Cadastradas no Departamento da Cana-de-açúcar e Agroenergia.. http://www.agricultura. gov.br/portal/page/portal/Internet-MAPA/pagina-inicial/vegetal/culturas/cana-de-acucar. (consultado em 25.07.2010)

MARTINEZ, Paulo Henrique (2006). História Ambiental no Brasil: pesquisa e ensino. São Paulo; Cortez.

SCHOWENGERDT, R. Antony (2007) - Remote Sensing - Models and Methods for Image Processing, Editora Academic Press.

SILVA, Sandro Dutra e; PIETRAFESA, José Paulo; TAVARES, Giovana Galvão (2011). As fronteiras do progresso e a devastação da natureza: frentes, marchas e expansão desenvolvimentista na exploração agrícola do Cerrado em Goiás. Anais do II Workshop Internacional de História do Ambiente: desastres ambientais e sustentabilidade \& GISDAY 2011. Florianópolis, SC. 